\title{
RESIDUAL STRESS DISTRIBUTION IN FEAI WELD OVERLAY ON STEEL
}

\author{
X.-L. Wang, S. Spooner, C. R. Hubbard, P. J. Maziasz, G. M. Goodwin \\ Z. Feng, and T. Zacharia \\ Oak Ridge National Laboratory, Oak, Ridge, TN 37831
}

\begin{abstract}
Neutron diffraction was used to measure the residual stress distribution in an FeAl weld overlay on steel. It was found that the residual stresses accumulated during welding were essentially removed by the post-weld heat treatment that was applied to the specimen; most residual stresses in the specimen developed during cooling following the post-weld heat treatment. The experimental data were compared with a plasto-elastic finite element analysis. While some disagreement exists in absolute strain values, there is satisfactory agreement in strain spatial distribution between the experimental data and the finite element analysis.
\end{abstract}

\section{INTRODUCTION}

FeAl alloys have been shown to exhibit outstanding high-temperature oxidation/corrosion resistance and therefore have great potential for use as corrosionresistant cladding in a variety of high-temperature structural applications [1]. Recently, several such $\mathrm{FeAl}$ alloys have been developed [2] with improved mechanical behavior and weldability. However, producing a crack-free cladding onto, for example, a steel substrate has proven to be a challenging task. In general, special preheat and post-weld heat treatment are required. Earlier welding research [2] revealed that while there was no hot-cracking during welding, substantial cold-cracking occurred during cooling of the weld overlay. This observation points to the residual stresses which developed during cooling as a result of the temperature difference and thermal expansion mismatch [3] between the FeAl deposit and the steel substrate. To understand the nature and development of these residual stresses, we have initiated a systematic investigation combining non-destructive neutron diffraction measurements and finite element modeling. In this paper, recent results obtained in a crack-free FeAl weld overlay deposited on steel substrate are described.

\section{EXPERIMENTAL}

The specimen used for residual stress analysis is schematically shown in Fig. 1. The $21 / 4 \mathrm{Cr}-1 \mathrm{Mo}$ ferritic steel substrate was given a standard normalization and tempering ( $1 \mathrm{hr}$. at $900^{\circ} \mathrm{C}+1 \mathrm{hr}$. at $700^{\circ} \mathrm{C}$ ) heat-treatment prior to welding. The FeAl alloy selected for weld-overlay has the following composition: Fe-35.8 Al-0.2 Mo-0.05 Zr-0.13C-0.01 $\mathrm{B}$ (at \%). The FeAl weld-overlay deposit was made using the GTA process with $200^{\circ} \mathrm{C}$ preheat and a post-weld heat treatment of $700^{\circ} \mathrm{C}$ for 2 hours followed by a furnace cool.

The residual stress measurements were conducted at the High Flux Isotope Reactor of Oak Ridge National Laboratory using a modified triple-axis spectrometer. A (1 01 1) reflection from a beryllium single crystal was used as the monochromator. The take-off angle for the monochromator was $90^{\circ}$ and the selected neutron wavelength was approximately $1.6 \AA$. For both materials (ferritic steel substrate and $\mathrm{FeAl}$ alloy), the bcc $(211)$ reflections were used for strain determination. The diffraction profiles were recorded with an ORDELA linear position-sensitive detector mounted at the analyzer position of the triple-axis spectrometer. The recorded peak profiles were fitted with a
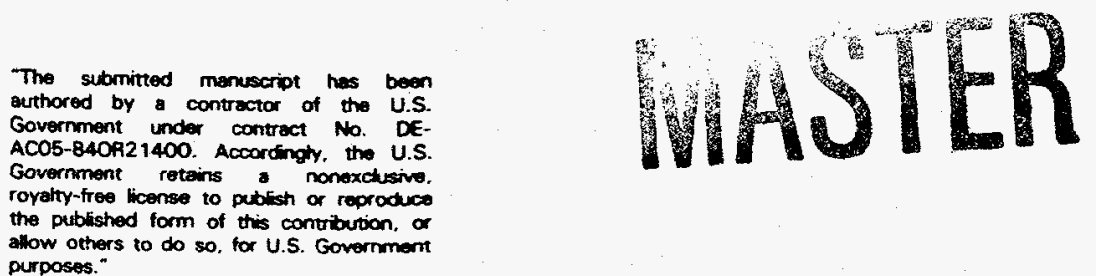


\section{DISCLAIMER}

Portions of this document may be illegible in electronic image products. Images are produced from the best available original document. 
Gaussian function to yield the position (20), intensity, and the width of the peak. The strains in each material were obtained using the equation

$$
\varepsilon=\frac{d-d_{0}}{d_{0}}=\frac{\sin \theta_{0}}{\sin \theta}-1,
$$

where $d$ is the lattice spacing of the reflection used for strain determination. $d_{0}$ and $2 \theta_{0}$ are the stress-free (reference) values. The sampling volumes were $2 \times 2 \times 2 \mathrm{~mm}^{3}$ for the steel substrate and $1 \times 1 \times 1 \mathrm{~mm}^{3}$ for the $\mathrm{FeAl}$ alloy, respectively. Strain mapping was accomplished using a three-dimensional translation system mounted on the sample table of the spectrometer.

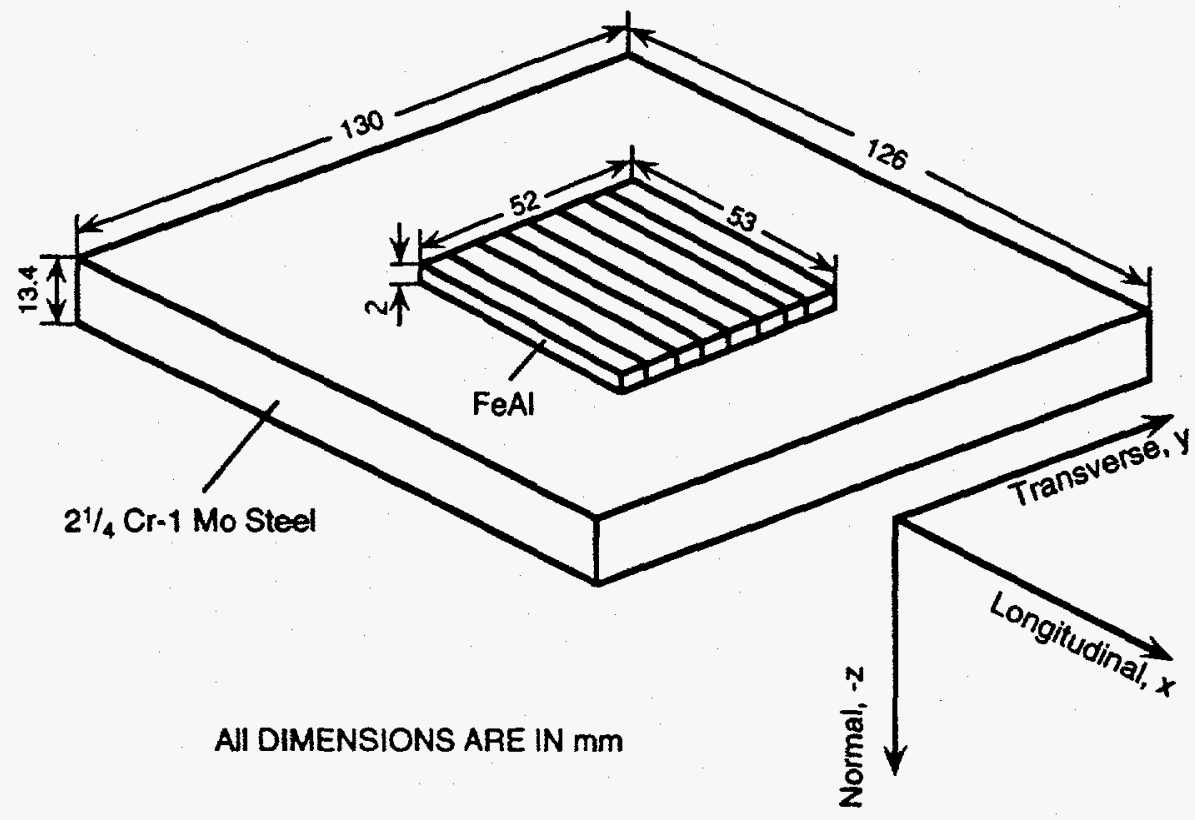

Fig. 1 A schematic drawing of the specimen used for residual stress analysis.

\section{RESULTS}

In Fig. 2, the longitudinal, transverse, and normal strains determined at the weld overlay center $(x, y=0)$ are shown as a function of depth $(z)$ in the ferritic steel substrate. The experimental data indicate that near the interface, the substrate is in compression along the $\mathrm{x}-\mathrm{y}$ plane and in tension in the $\mathrm{z}$ direction. For all three components, the measured strains decrease in magnitude with increasing distance from the interface and eventually change sign as the back surface is approached. To assess whether a shear strain exists in the $x-y$ plane, the in-plane strains were measured as a function of rotation angle around the $z$-axis. To within the experimental precision, the in-plane shear strain was found negligible.

Comprehensive strain maps were obtained at depths $z=-3.0,-6.5$, and $-10.0 \mathrm{~mm}$ from the interface for all three components. Considering the symmetry of the specimen, only one quadrant was surveyed. In all cases, the measured strains were quite small, ranging from $-5 \times 10^{-4}$ to $2 \times 10^{-4}$. Fig. 3(a) shows the strain maps obtained at $\mathrm{z}=-3.0 \mathrm{~mm}$. As can be seen, all three strain components vary strongly as a function of $(x, y)$ (measured from the weld overlay center) at this depth. Experimental data obtained at other depths indicate that these strain variations diminish with increasing distance from 
the interface. At $z=-10.0 \mathrm{~mm}$, the measured strains were virtually constant throughout the sampled area.

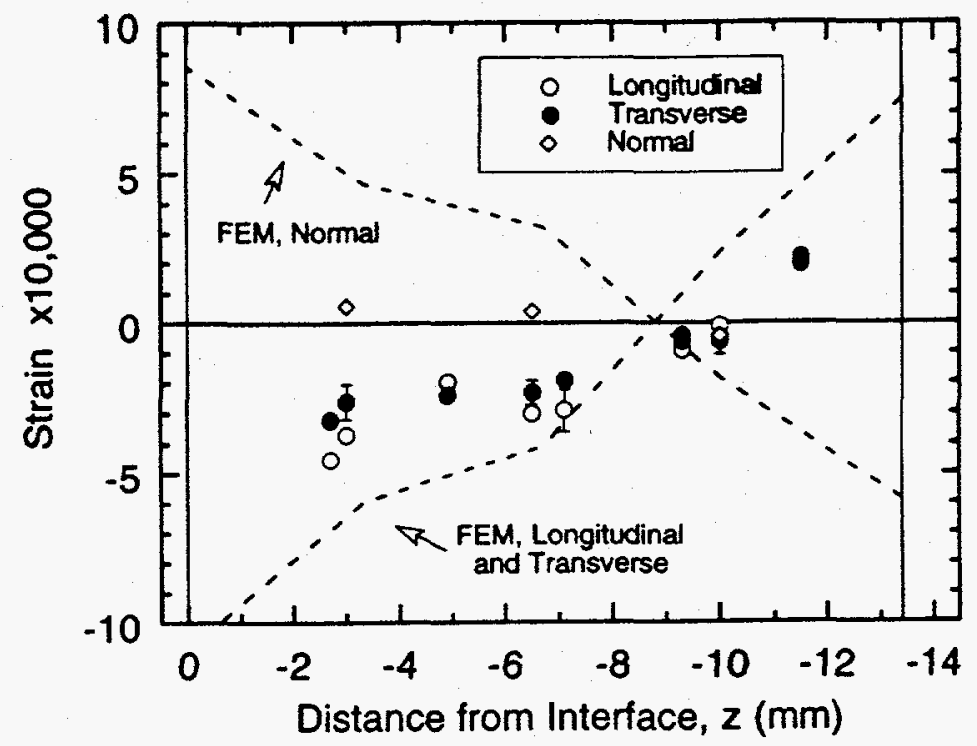

Fig. 2 Depth dependence of longitudinal, transverse, and normal strains at the center of the weld overlay in the ferritic steel substrate. For clarity, representative error bars are plotted. The solid vertical lines are the boundaries of the substrate. The dashed lines are finite element calculations.
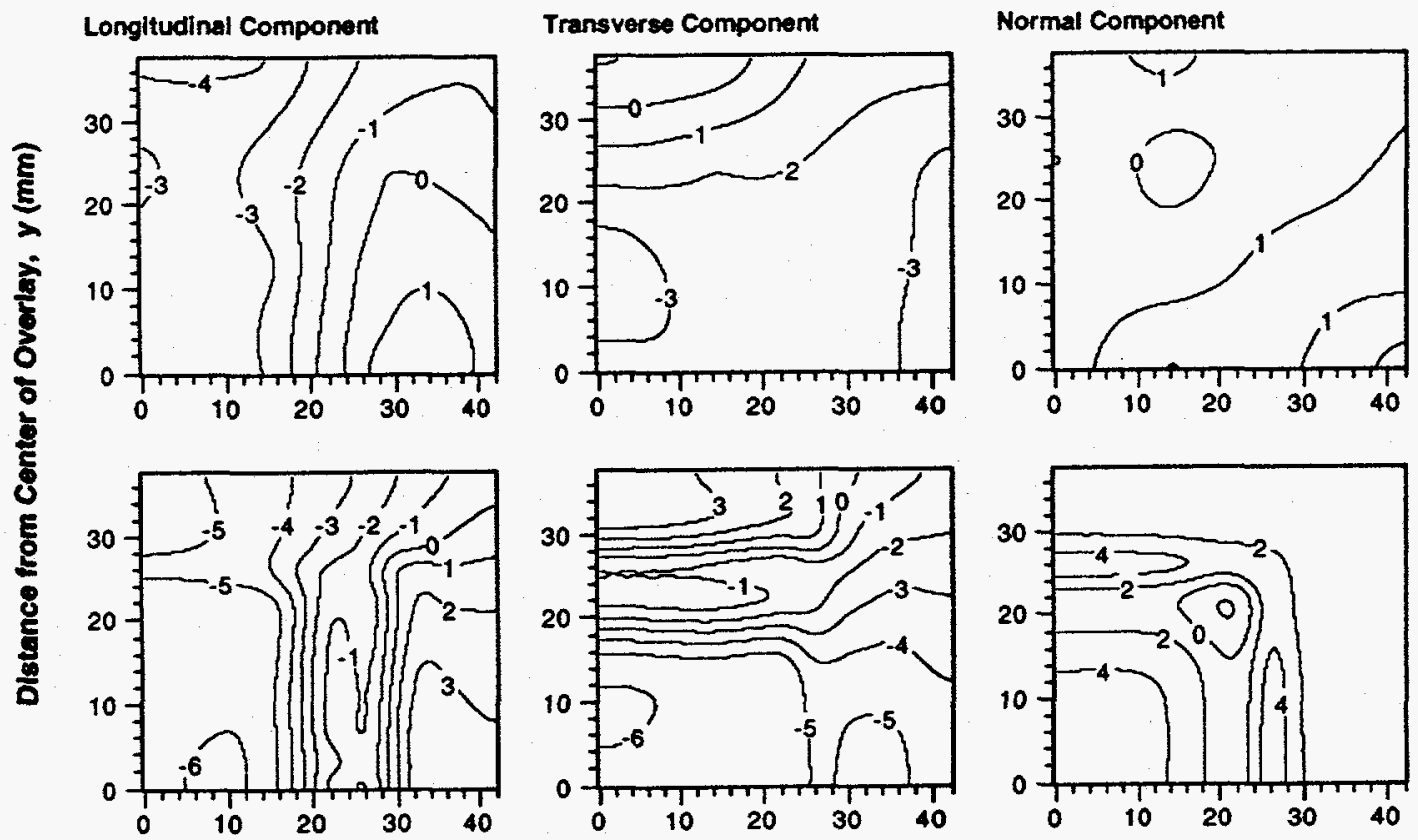

(a)
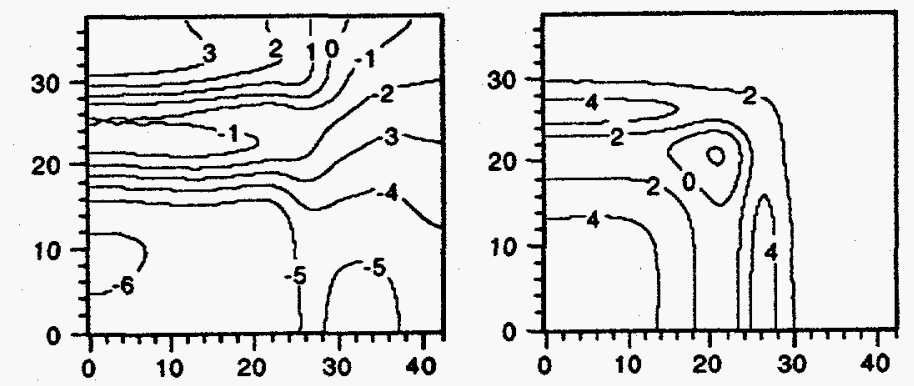

Distance from Center of Overlay, $\mathbf{x}(\mathrm{mm})$

Fig. 3 (a) Experimentally determined strain maps at $z=-3.0$ in the steel substrate. (b) Finite element calculations. The strains are in units of $10^{-4}$. 
Strain determination in the FeAl weld layer was hampered by the large grains $(\sim 0.2$ $\mathrm{mm}$ ) present in the material. Rocking curve experiments at selected positions in the weld revealed that only a handful of grains were contained within a $1 \mathrm{~mm}^{3}$ sampling. As a result, the strain along a particular specimen orientation cannot be directly measured at all locations. Because of this, we have not been able to map the strains in the FeAl weld. (To do so, a complete analysis of the full strain tensor of individual grains is required.) Measurements, however, have been made along the longitudinal and normal directions at locations where grains are favorably oriented to give a measurable (2 111 ) peak. The obtained $2 \theta$ in each measurement series was then averaged to minimize possible peak shift due to the small number of diffracting grains. The averaged $2 \theta$ were $86.035^{\circ} \pm 0.093^{\circ}$ and $86.376^{\circ} \pm 0.061^{\circ}$, respectively, for the longitudinal and normal directions. Since $2 \theta_{0}$ was unknown, owing to the lack of a fine-grained reference specimen, the strain values cannot be determined from the measured $2 \theta$. However, as will be seen below, under a bi-axial stress assumption the longitudinal stress can be estimated without the need of $2 \theta_{0}$. Assuming a biaxial-stress state, the above $2 \theta$ indicate a tensile stress along the longitudinal direction.

\section{DISCUSSIONS}

As noted earlier, both the temperature difference and thermal expansion mismatch between the FeAl weld deposit and the steel substrate contribute to the residual stress buildup. The former is a non-equilibrium process and the residual stress thus generated can be labeled as welding stress. The latter is an equilibrium process, with uniform temperature throughout the specimen during cooling. The residual stresses generated in this process are similar to those in ceramic-metal joints $[4,5]$ and hereafter referred to as joining stress. The depth dependence of the experimental data shown in Fig. 2 is characteristic of residual stresses due to the joining $[4,5]$. Because FeAl has a higher coefficient of thermal expansion [3], it is expected that the steel substrate is in compression and the FeAl in tension along the surface of the specimen, as was evidenced from the experimental data. The smaller strain in the substrate is consistent with the relatively smaller thickness of the weld overlay. As can be seen from Fig. 3(a), the strain concentrations occur near the edges of the weld overlay deposit. This is also typical of the stress distribution [5] in joints of dissimilar materials. These results strongly suggest that the welding stress in the specimen was essentially removed by the post-weld heat treatment. A further piece of evidence supporting this suggestion is that the width of the ferrite $(211)$ reflection is almost resolution limited throughout the substrate. In a typical welded structure, the width of a diffraction peak increases considerably in the heat affected zone [6] due to the plastic deformation that occurred during non-equilibrium cooling.

Assuming the principal stress directions are along the $\mathrm{x}-, \mathrm{y}-$, and $\mathrm{z}$-axis, the residual stresses in the substrate can be deduced by using,

$$
\sigma_{i}=\frac{E}{1+v}\left[\varepsilon_{i}+\frac{v}{1-2 v} \sum_{j} \varepsilon_{j}\right]
$$

with $i$ (or $j)=x, y, z$. In this equation, $E$ is the Young's modulus and $v$ the Poisson's ratio of the substrate. For ferritic steel, $E=200 \mathrm{GPa}$ and $v=0.3$. For illustration, the calculated residual stresses at the center of the weld overlay are shown in Fig. 4. As might be expected from the strain data, the residual stresses in the substrate are small ( $<150 \mathrm{MPa}$ ). All three stress components are compressive, suggesting a hydrostatic stress exists at the center of the weld overlay. 
Under a bi-axial stress state, the longitudinal stress in the $\mathrm{FeAl}$ weld is given by,

$$
\sigma_{x}=\frac{E}{1+v}\left(\varepsilon_{x}-\varepsilon_{z}\right)=\frac{E}{1+v} \cdot \frac{\sin \theta_{z}-\sin \theta_{x}}{\sin \theta_{0}} .
$$

Since the thickness of the weld layer was much smaller than the lateral dimensions, the bi-axial stress assumption was deemed reasonable. In calculating $\sigma_{x}, \theta_{0}$ can be substituted with the average of $\theta_{x}$ and $\theta_{z}$ without introducing undesirable uncertainties. Assuming $E=180 \mathrm{GPa}$ [7] and $v=0.3$, a tensile stress of $429 \pm 140 \mathrm{MPa}$ was obtained for the FeAl weld along the longitudinal direction. This level of stress approaches the yield strength in these $\mathrm{FeAl}$ alloys, which ranges from 400 to $530 \mathrm{MPa}$ [2] at room temperature.

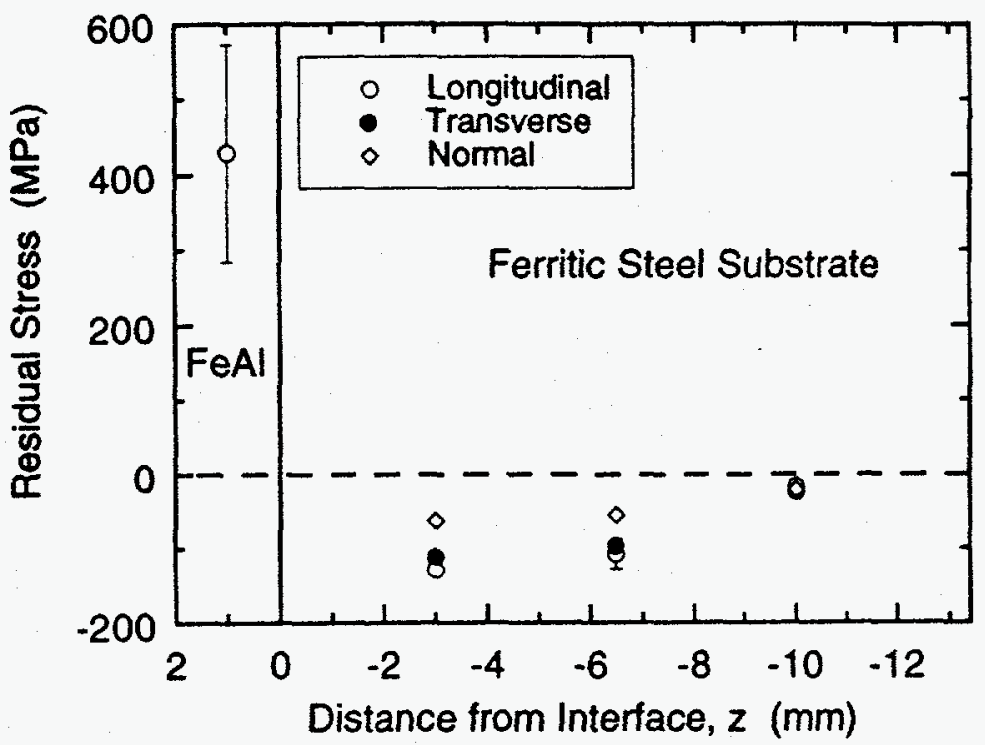

Fig. 4 Residual stresses in the FeAl weld overlay specimen. Data in the ferritic steel substrate are for locations at the center of the weld overlay. Data in the FeAl weld represent an average over all locations where the longitudinal strain can be directly measured (see text). For the substrate, the estimated standard deviations are plotted for one data point for clarity.

To obtain a quantitative comparison with the experimental data, a plasto-elastic finite element model was developed using the commercial ABAQUS code [8]. Basically, the model considers the residual stress buildup in three steps: simulated welding, postweld heat treatment, and subsequent furnace cooling. Details of the model and input parameters will be reported elsewhere [9]. The modeling results confirmed that most residual stresses accumulated during welding were removed during post-weld heat treatment, and the residual stresses in the specimen arose predominately during furnace cooling. In Fig. 2, the results obtained from the model are superimposed with the experimental data. Notice that in the finite element analysis, the longitudinal and transverse components are identical at the weld overlay center, because of the symmetry of the specimen. As can be seen in Fig. 2, the finite element calculations are in excellent agreement with the general trend of the experimental data. More strikingly, the model predicts a rapid increase in strain near the interface. The strain data in Fig. 2 indeed show such tendency. Fig. 3(b) shows the same set of strain maps as in Fig. 3(a) but calculated 
by the finite element model. Except for the normal component, the model and experimental data are in satisfactory agreement. Substantial disagreement exists, however, in absolute strain values. This could be due to the materials data and/or welding parameters assumed in the model. Also, the experimental data represent an average over a selected sampling volume. To directly compare with the experimental data, appropriate averaging must be taken into account in the finite element analysis.

\section{CONCLUDING REMARKS}

With special preheat and post-weld treatment, crack-free FeAl weld overlay can be made onto a $21 / 4 \mathrm{Cr}-1$ Mo steel substrate. The present neutron diffraction experiment and finite element modeling reveal that the post-weld heat treatment is important in that it relieved the large residual stresses accumulated during welding. Most residual stresses in the specimen developed during cooling following the post-weld heat treatment.

Nevertheless, while the residual stresses are small and compressive in the steel substrate, they are large and tensile in the FeAl weld overlay. The finite element model developed for this application has been demonstrated to provide adequate description of the experimentally determined residual strain distribution. It is hoped that this model, upon refinement, can be used as a guide to actual processing practice to further reduce the residual stresses so that crack-free cladding can be made with minimal preheat and postweld heat treatment procedures.

\section{ACKNOWLEDGMENT}

This work was supported by the U. S. Department of Energy, Assistant Secretary for Energy Efficiency and Renewable Energy, Office of Transportation Technologies, Advanced Industrial Materials Program and by the Office of Transportation Technologies as part of the High Temperature Materials User Program under contract DE-AC05$840 R 21400$ with Martin Marietta Energy Systems, Inc.

\section{REFERENCES}

1. C. T. Liu, V. K. Sikka, and C. G. McKamey, Alloy Development of FeAl Alloys for Structural Use in Corrosive Environments, Oak Ridge National Laboratory, ORNLTM-12199 (February 1993)

2. P. J. Maziasz, G. M. Goodwin, C. T. Liu, and S. A. David, Scripta Metall. Mat., 27, 1835 (1992).

3. W. D. Porter and P. J. Maziasz, Scripta Metall. Mat., 29, 1043 (1993).

4. O. T. Iancu, D. Munz, B. Eigenmann, B. Scholtes, and E. Macherauch, J. Am. Ceram. Soc., 73, 1144-49 (1990).

5. X.-L. Wang, C. R. Hubbard, S. Spooner, S. A. David, B. H. Rabin, and R. L. Williamson, submitted to Mat. Sci. Eng.

6. P. J. Webster, pp. 95 in Proceedings of 3rd International Conference on Trends in Welding Science and Technologies, ASM, Materials Park, OH 44073

7. J. H. Schneibel, " Selected Properties of Iron Aluminides," pp. 329-42 in Processing, Properties, and Applications of Iron Aluminides, J. H. Schneibel and M. A. Crimp, eds., TMS, Warrendale, PA (1994).

8. ABAQUS Releases 5.3-1, Hibbitt, Karlsson \& Sorensen, Inc., Pawtucket, RI (1993).

9. Z. Feng et al., unpublished.

\section{DISCLAIMER}

\footnotetext{
This report was prepared as an account of work sponsored by an agency of the United States Government. Neither the United States Government nor any agency thereof, nor any of their employees, makes any warranty, express or implied, or assumes any legal liability or responsibility for the accuracy, completeness, or usefulness of any information, apparatus, product, or process disclosed, or represents that its use would not infringe privately owned rights. Reference herein to any specific commercial product, process, or service by trade name, trademark, manufacturer, or otherwise does not necessarily constitute or imply its endorsement, recommendation, or favoring by the United States Government or any agency thereof. The views and opinions of authors expressed herein do not necessarily state or reflect those of the United States Government or any agency thereof.
} 